MPC MAJOR RESEARCH PAPER

THE POWER OF SOCCER FANDOM IN TORONTO

\title{
ANDREA ZDZYLOWSKI
}

\section{DR. CAROLYN MEYER}

The Major Research Paper is submitted in partial fulfillment of the requirements for the degree of Master of Professional Communication

\author{
Ryerson University
}

Toronto, Ontario, Canada

September 08, 2011 


\section{AUTHOR'S DECLARATION}

I hereby declare that I am the sole author of this Major Research Paper (MRP).

I authorize Ryerson University to lend this MRP to other institutions or individuals for the purpose of scholarly research.

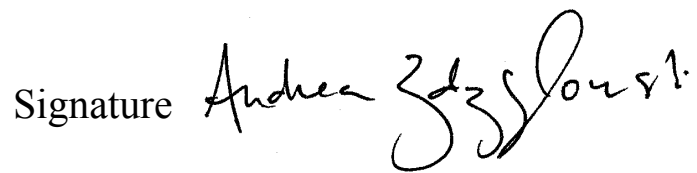

I further authorize Ryerson University to reproduce this MRP by photocopying or by other means, in total or in part, at the request of other institutions or individuals for the purpose of scholarly research.

Signature Andrea $2 d z y_{0}$ Yor 


\begin{abstract}
This Major Research Project will examine two distinct fan cultures associated with the Toronto FC soccer team-The Red Patch Boys and U-Sector-and the ways in which individuals part of both fan cultures use social media, social networking, and online applications in order to communicate. Both fan cultures are prominent during each Toronto FC home game, but they also have a large online presence which enables fans to connect to one another regardless of their location. This virtual presence highlights the value of online applications and the power of fandom.

Thematic discourse analysis was used in order to analyze the information collected through observations at Toronto FC home games and on both fan cultures' official Twitter accounts, websites, and online forums. Through this analysis, the themes of hierarchy and Toronto FC related material became prominent.
\end{abstract}

Since this MRP focuses solely on two fan cultures, The Red Patch Boys and U-Sector, it must be noted that these results may not be applicable to all fan communities. Further research must be conducted before the definite impact of new media applications on fan cultures can be concluded. 


\section{ACKNOWLEDGMENTS}

I would like to take the time to thank the following people for assisting and providing me with their feedback, support, and compassion while writing my MRP:

Dr. Carolyn Meyer - Thank you for the encouragement, support, and suggestions. Your consistent feedback not only helped me to stay on schedule, but it pushed me into writing a welldeveloped paper.

Dr. Catherine Schryer - Thank you for acting as my Second Reader and introducing new ideas to my project.

Steven Zdzylowski - You were my shoulders to cry on during this whole endeavour. You were there for all of the ups and downs, and always believed that I was capable of more. (Also, this was our year of concerts!)

Carly Popenko - Thank you for acting as my second set of eyes. You consistently critiqued my work and pushed me to try harder. Your familiarity with my writing style gave you the ability to motivate me into creating my best paper yet.

Nancy and Edward Zdzylowski - Thank you for being great parents, and reminding me to work on my MRP. 


\section{TABLE OF CONTENTS}

Author's Declaration $\quad$ ii

$\begin{array}{ll}\text { Abstract } & \text { iii }\end{array}$

Acknowledgments $\quad$ iv

$\begin{array}{ll}\text { Introduction } & 06\end{array}$

$\begin{array}{ll}\text { Literature Review } & 11\end{array}$

$\begin{array}{ll}\text { Methodology } & 25\end{array}$

$\begin{array}{ll}\text { Results and Discussion } & 27\end{array}$

$\begin{array}{ll}\text { Conclusion } & 54\end{array}$

$\begin{array}{ll}\text { Works Cited } & 57\end{array}$ 


\section{INTRODUCTION}

In 2005, a new professional sports team, part of Major League Soccer (MLS), was introduced to Toronto, Ontario that brought attention to the popularity of soccer and inspired the growth of the sport within Canada. The team was called Toronto FC (Toronto Football Club), and was not met with positive reviews upon its initial public reveal. The public were skeptical of the success of another sports team within a city already so involved with a losing NHL (National Hockey League) franchise. Additionally, Toronto had its share of problems in filling arenas for its local NBA (National Basketball Association), AHL (American Hockey League), and MLB (Major League Baseball) team home games. However, despite the unsteady start of the team, winning only six out of a possible thirty MLS regular season games in their inaugural 2007 season ("Statistics"), a long-term sponsor/partnership formed between Toronto FC, Maple Leaf Sports and Entertainment (MLSE), the City of Toronto, and the Provincial Government of Ontario so a team stadium could be constructed. The newly developed field was named BMO Field through a naming partnership with the Bank of Montreal and was "[b]uilt in 468 days, on time and on budget (\$62.9 million)" (CNW). After the stadium was completed, no one, including the MLS, MLSE, and the City of Toronto, could have expected the success of the team and the instant loyalty from the team's fans.

Toronto FC is now in their fifth season of the MLS and has yet to make the playoffs. In their time, Toronto FC has only accomplished one major milestone: in 2009, 2010 and 2011, the team successfully captured the Canadian Nutrilite Cup. However, since there are only three other teams that compete for the Cup, this accomplishment is not recognized by a large audience. 
Despite the lack of achievements by the Toronto FC (Fitz-Gerald), and the introduction of new successful MLS teams such as Philadelphia Union (which were able to bring Toronto to their greatest loss date-6-2 during a home game at BMO Field), fans of the Toronto FC continue to cheer-on a losing MLS franchise with an uncertain future.

Toronto FC fans are unique, loyal, and dedicated individuals who are not only soccer fans, but people who have actively made themselves a part of the Toronto FC game day experience. The fans are known throughout the MLS circuit for road-tripping to other stadiums across Canada and the United States in order to cheer on the team, and for making their presence known at other venues, sometimes even being louder than the home team's supporters. An example of such energy can be seen back in 2009 when Columbus Crew officials "....estimated that more than 1,500 Toronto fans made the trip to Ohio" (Fitz-Gerald) for the home opening game of MLS season between the Toronto FC and Columbus Crew. This type of long-distance travel may not seem to be out of the ordinary until you look at the audience statistics. Out of the whole stadium, those 1,500 Toronto FC fans made up more than ten percent of the 14,886 attendees at the home opening game (Fitz-Gerald). Toronto FC fans are using their own money, resources, and time to support a team that the National Post recently speculated to be Major League Soccer's worst team (Fitz-Gerald). Before addressing this issue any further, it is important to differentiate these active (as opposed to casual) Toronto FC fans into two groups who particularly embody their fandom to immeasurable levels: The Red Patch Boys and USector.

Various types of fans attend Toronto FC games. There are those who purchase tickets to a 
single game, those who win tickets, those who are season/half-season ticket holders, and those who attend in order to cheer-on an opposing team. Despite how frequently one may attend Toronto FC home games or purchase a certain type of ticket, there are two specific fan cultures linked to the Toronto FC team that seem to heavily impact the game's environment. These fan cultures do not discriminate and treat each person who purchases a membership with equality, respect, and a recognition that they too are true supporters of the Toronto FC team. These fan cultures also have made themselves a part of the gaming environment despite not being directly associated with the MLSE, MLS, or the Toronto FC team. The Red Patch Boys and U-Sector are two fan cultures consisting of people who are Toronto FC supporters. These fans typically sit in sections 111, 112 and 113 at the BMO field on game days, and tend to be loud, energetic, supportive, and educated about all things related to the Toronto FC. However, instead of only showing support on game days, these fan cultures also use online social networking and media applications in order to communicate with one another and to create a unified fan culture identity. Both fan organizations have a known presence on Twitter and Facebook, as well as various online message boards that enable fans to share comments, feedback, and information. I believe that these social media and social networking technologies have not only provoked a new type of fandom, but have also caused a new type of fan culture to emerge. Without these new online applications, I believe that U-Sector and the Red Patch Boys would not be as prominent or as influential in the Toronto FC soccer environment as they are today.

For example, last year these fan organizations orchestrated a silent protest by using social media and social networking to connect fans together and to express their concerns. The event 
occurred on October 16, 2010 at the BMO Field, “.... a stadium renowned for its game-day atmosphere, [and] from the start [of the game], silently-protesting fans among the 18,084 on hand made the ambiance downright funereal" (Wolstat). The event highlighted how important fans are to the Toronto FC game day atmosphere. At almost every Toronto FC match, regardless of the attendance numbers, fans make their presence known by cheering, chanting, clapping, and singing. On this occasion, however, the Red Patch Boys and U-Sector fans were silent in order to demonstrate just how unhappy they were with the team, the MLSE's increase in ticket prices, and the lack of funding for the Toronto FC. Without social media at their disposal, fans would have not been able to unite to show their concerns. I believe that Twitter, Facebook, and online message boards have enabled fans to become part of the Toronto FC soccer environment without being directly associated with the MLSE, MLS, or the Toronto FC franchise. These online applications have allowed fans to break news, discuss rumours, and plan for events to be carriedout during live games. Therefore, it is important to research these types of fan cultures because not only are they supporting a team with an uncertain future, they are also showing how influential new social media and social networking can be in modern sports environments.

Studying and researching fan cultures will enhance our understanding of the success, failures, and overall impact of new media and social networking applications in a widespread public environment. If a web application is used by many individuals who are part of a fan culture, it may prove how successful the device is in bringing people together, forming communities, and implementing social action—essentially, how useful, influential, and significant a new media device may be. Additionally, fan cultures can be considered as markers 
that indicate the longevity and popularity of certain products, people, or events (Bruner and Thorne). For example, music history has shown that the most successful musicians with the longest career span have an avid fan culture following them-Lady Gaga (and her Monsters), Britney Spears, and even Madonna have all proved the old saying, one is nothing without fans. This sentiment can also be transferred to other areas of popular culture, such as underground cinema and the fans of the horror film Troll 2. Troll 2 was rated by Rotten Tomatoes, an online social film critic site, as being the worst movie ever made (“Troll 2 - Rotten Tomatoes"). Yet, because of the avid fan culture that surrounded this film years after its initial release, Troll 2 was re-released in 2010 ("Troll 2 (The $20^{\text {th }} \ldots$.."), and a follow-up documentary, Best Worst Movie, was made. The documentary studied those who had become part of this particular underground cinematic fan culture. Overall, fan cultures are fascinating creations that allow people who share a common interest to join together to support or provoke social change. By studying fan cultures and looking at Toronto FC fans, I will see how fans impact the environment at the BMO Field, and how fan cultures affect an organization, league, and team that they are not directly affiliated with. Fans are no longer just a viewing audience, but are powerful entities with one large voice that have the ability to impact the future of the teams that they worship. 


\section{LITERATURE REVIEW}

Considering fan cultures are linked to a variety of different popular culture groups, places, and people, it is important to research how fan cultures exist on a general scale. Most literature available on fan cultures focuses on designating a fan culture (Moor), monitoring fan behaviour (Bruner and Thorne), studying fan formation (Smith), and researching the types of individuals who participate in such counter/subcultures (Gray). Recent articles have even attempted to link fan cultures to media convergence and the development of new technologies (Jenkins).

Liz Moor, a researcher who has analyzed the logistics of fan cultures associated with European football, believes that fan cultures need to be more clearly researched and understood. Moor reflects on how fan cultures strive to relate back to an individual's class, yet if “...class is to remain a useful concept for research in this area, its meaning and relationship to different variables need to be clarified" (Moor 137). Moor questions the current ways in which judgements are made around fan cultures and poses new areas of interest and concern. For instance, Moor showcases how most people part of fan cultures are assumed to be part of a certain class status and are thought to be over-the-top when participating in such types of counter-cultural groups. Moor emphasizes that quick judgements should not be made about fans, as those who are part of fan cultures can vary in stature, class status, and overall appearance (thus making it difficult to understand who is a real fan, and who is present for other reasons) (Moor 138). To further this point, Moor relates the issue back to the constant need for fans and media to differentiate who is part of a fan culture and who is an outside observer (Moor 138). By endorsing this need for differentiation, fan cultures may be attempting to degrade or lower the 
class status of another group in order to raise their own. Moor believes that football and fan cultures should not be directly linked to consumption and consumerism. Understanding and relating fan cultures to material goods and consumption "...leads to a tendency to see all other shifts in fandom as a consequence of commodification rather than as having any autonomy of their own or indeed as being related to other non-market forces" (Moor 139). Moor uses this idea as a way of articulating the power of fandom and why it should not be assumed that fans are dependent on consumption and market factors alone. Moor ends her article by stating that fans are not watching football and other sports because of marketing. As such, researchers need to stop, “...ignoring the fact that many 'traditional' supporters may make use of the Internet as well as television and radio, and that newer fans may prefer a more 'virtual' relationship to football"' (Moor 139). On the other hand, researchers Scott Thorne and Gordon Bruner focus on fan cultures from a North American stance and showcase how fans alter their behaviour once they have immersed themselves within a fan culture and consequently become part of a group that is of corporate interest.

Thorne and Bruner state that fan cultures in America are important because they create consumer markets that advertisers can easily reach (Bruner and Thorne 15). Fan cultures exist because fans "focus their time, energy, and resources intently on a specific area of interest...Fans usually have a strong enough interest that small to major changes in their lifestyles are made to accommodate devotion to the focal object" (Bruner and Thorne 53). Such changes in lifestyle stem from the fans' need to accommodate their new area of interest, which in turn affects their overall consumption patterns and behaviours. Thorne and Bruner's argument focuses on this 
correlation and suggests that corporations market to fans "due to [marketing] pervasiveness in our society and the impact [marketing] has on the economy... [Additionally,] the time is ripe for social researchers to shed some much needed light on the phenomenon of fan culture" (Bruner and Thorne 68). Conglomerates believe that fans are passive individuals, yet Thorne and Bruner highlight that fans think for themselves and that their fandom and loyalty to a certain person, place, or thing comes first. Past studies in the field have focused on issues pertaining to fan cultures that may not be applicable to a large audience and have "examined the importance of key internal characteristics and their relationships to the level of fanaticism present, nor how self-reported fanaticism is related to fan behaviour" (Bruner and Thorne 65). Thorne and Bruner address how preconceived notions of fan culture should be forgotten because "there are common characteristics across several different genres of fans and that these characteristics are neither extreme nor aberrant" (Bruner and Thorne 65). They discuss how fans strive to be part of an internal community, but do not resort to drastic action once they are established within the group (Bruner and Thorne 65). These fans participate in a variety of activities such as posting to web communities, talking with other fans at events, and discussing their interests with other fanatics. These actions are common with many different types of fan cultures but are rarely acknowledged. Instead, the media and other outsiders focus on the negative, sensationalist events involving these groups. In addition to addressing issues around fan behaviour, Thorne and Bruner also discuss the relevance of increased computer-moderated fan interactions.

Bruner and Thorne explain how "fans often desire more interaction and external involvement than is provided for by the official site and create their own discussion groups, 
bulletin boards, chat rooms and web sites, allowing them to develop secondary material and share it with others" (Bruner and Thorne 66). Chat rooms, online bulletin boards, and online forums give fans a place to have opinions and express their concerns; fans can feel even more connected to their fan culture environment (Bruner and Thorne 67). These places are also desired by corporate officials as they become "lucrative to capitalize on...developing secondary materials for fans or co-opting fan created activities and materials" (Bruner and Thorne 68). These online fan cultures can enable officials to encourage, manipulate, and push a further understanding of the concerns of certain groups (Bruner and Thorne 67). However, researcher Jonathan Gray sees fan cultures differently, and believes that certain fan types are more influential than others.

Gray focuses on anti-fans, non-fans, and fans that exist within a functioning society. Gray initially addresses anti-fans as those who voice negative opinions online and in-person while working to "construct an image of [a] text-and, what is more, an image they feel is accuratesufficiently enough that they can react to and against it" (Gray 71). These anti-fans are important to study despite their ongoing negative feedback because they allow a researcher to see differences "in the text itself as perceived by close or 'distant' readers" (Gray 71). These antifans make themselves part of an environment which they dislike, thus demonstrating a form of fandom and loyalty to their cause. Gray classifies another type of fan group as the non-fans who "do view or read a text, but not with any intense involvement" (Gray 74). These non-fans cannot be described as "real fans" because "Being a fan requires discipline, whereas being a non-fan is considerably more open and nebulous a category and practice, involving considerable flow in 
and out of different viewing positions" (Gray 74). Non-fans vary in viewing engagement, which makes it difficult to judge their interests when their priorities are constantly shifting (Gray 77). Gray places importance on understanding “...anti-fans and non-fans as well, and study how [a] text changes-what atomic forces are at work-as it meets different audiences and viewing environments" (Gray 79). Taking Gray's argument into consideration, how will new electronic and mobile devices affect the ways in which fan cultures communicate within their environment? These new technologies are enabling fans to create websites and social media accounts that allow fans from around the world to connect in one locale. However, is this a positive change or are these changes affecting fan cultures negatively? Will new online locations remove/minimize the face-to-face interactions that occur between fans? Further elaborating on this issue is the work of Matthew J. Smith, a researcher with a focus on community development within the virtual online world.

When discussing online fan activity, Matthew J. Smith uses the term virtual communities. Virtual communities are described as being communities that form within a virtual setting (thus forcing members to use the Internet and new media devices). Here, interaction between community members is computer mediated, deeming face-to-face interactions unnecessary. Unlike physical interaction, the communication within virtual communities allows "for the same feeling of community without the requirement that all users be on the network at the same time" (Smith 87). Despite focusing his argument on the ways in which E-Zines have spread and become a way of communicating within a fan culture, Smith's arguments can be related to fan culture websites because they contain the same type of information that would be displayed 
within an online magazine (but in web form). Smith articulates how online features "incorporate the audience into the act and build, rather than limit, the size of the community" (Smith 93). Online items, such as fan sites, graphics, blogs, and webzines created by fan organizations enable up-to-date content that is relevant, strategically placed, and visually appealing to be posted in order to help to define who they are and what they stand for (Smith 93). Fan cultures that create these online items are working to define a future generation by providing information to others that can change society faster than ever before (Smith 96). Smith concludes his argument by stating how "the presence in virtual space of people who share one's interests help individuals find a sense of belonging that might otherwise be missing in their lives" (Smith 97). In short, Smith recognizes that virtual communities can create long-term relationships between people, as well as environments where news and information can be transferred quickly. Smith concludes the article by questioning whether the online world is one of communication potential or inactivity (Smith 97). Henry Jenkins has attempted to answer this question by linking fan cultures to new electronic technologies and devices.

Henry Jenkins's article, “The Cultural Logic of Media Convergence”, focuses on the idea that media is transformed by more than just technological development. Jenkins consistently poses questions regarding whether fan cultures are dictating the ways in which new media are developed, if corporations should form bonds with this dedicated group of individuals, and if "fan communities [will] be the new beneficiaries of audience measurement" (Jenkins 38). Jenkins's research contains numerous real-life examples that show how fan cultures form and the influence they have on society. Jenkins discusses how fans "of a popular television series may 
sample dialogue, summarize episodes, debate subtexts, create original fan fiction, record their own soundtracks, make their own movies-and distribute all of this worldwide via the internet" (Jenkins 34), and how "game companies have seen the value of constructing, rather than shutting down, fan communities around their products and building long-term relationships with their consumers" (Jenkins 40). Jenkins focuses on relationships that fans develop with a person, place, or thing, as well as the various issues that need to be resolved between fans and producers (Jenkins 38). Jenkins links fan cultures back to intellectual property arguments (because fan cultures typically share and redistribute copyrighted material) and asserts that "In the new media environment, it is debatable whether governmental censorship or corporate control over intellectual property rights poses the greatest threat to the right of the public to participate in their culture" (Jenkins 40). By addressing this issue, Jenkins showcases how new media may be a fragile environment where fans are limited in control. Government officials, as well as cable providers and local police, have the ability to monitor the online web usages of a fan culture and can see if users are taking content from other websites and violating intellectual property rights. Fan cultures in the past may have been able to take content from magazines, books, and other published materials in order to form their own fan art (which could be displayed at fan conventions or fan gatherings), but many such forms of expression are no longer classified under the Fair Use copyright law. Jenkins's supporting research provides a broad understanding on fan cultures, and illustrates the conditions in which they either flourish or flounder. Taking this information into account, this research project will also relate findings back to Activity Theory (Nardi) and Structuration Theory (Giddens) to help aid in the interpretation of document patterns 
and themes.

Activity Theory was created by Alexei N. Leont'ev and Sergei Rubinshtein as a "research framework and set of perspectives originating in Soviet psychology in the 1920s" (Nardi 7). According to Leont'ev and Rubinshtein, activity theory focuses on "perception, recognition, attention, memory, imagination, thinking, and emotion [as] not merely derived from activity but are themselves interpreted as forms of activity" (Zinchenko 286). Considering the theory continues to be altered and reworked, this paper will focus on Activity Theory as defined by researcher Bonnie A. Nardi. Nardi, a researcher whose primary focus is in defining Activity Theory, states that "Activity theory incorporates strong notions of intentionality, history, mediation, collaboration and development in constructing consciousness" (Nardi 7). At the same time, "Activity theorists argue that consciousness is not a set of discrete disembodied cognitive acts (decision making, classifications, remembering), and certainly it is not the brain; rather, consciousness is located in everyday practice: you are what you do" (Nardi 7). By using Activity Theory, the researcher can make hypotheses about why people act they way they do in some settings but not in others, and why they change in their opinions when part of a group setting. Activity Theory allows for correlations to be made between past and present events, and can be especially useful in explaining why fans may show different emotions or speak in a different way when they act as a fan individually and when they act as a fan part of a large group.

Structuration Theory is a theory created by Anthony Giddens in the 1980 s as a means to become "The basic domain of study of the social sciences, according to the theory of structuration, is neither the experience of the individual actor, nor the existence of any form of 
social totality, but social practices ordered across space and time" (Giddens 2). Structuration Theory is of use when determining the logistics behind communicative repetition and how social systems function. Structuration Theory states that the majority of human functions and decisions are predetermined and are thus governed by some type of rule and regulation system. Since the definition of Structuration Theory is fairly recent, Giddens's definition of the theory will be explored. As stated by Giddens, the theory involves “...structuring of social relations, aspects which, in the theory of structuration, are grasped by recognizing a differentiation between the concepts of 'structure' and 'systems' (Giddens 17). Additionally, "One of the main propositions of Structuration theory is that the rules and resources drawn upon in the production and reproduction of social action are at the same time the means of system reproduction (the duality of structure)" (Giddens 19). Therefore, when using Structuration Theory, it is important to analyze data in a way that illustrates how habits, routines, and rules influence how humans interact with one another. For instance, how may an online environment limit or manipulate communication between a group of individuals? What elements are users unable to edit or modify when having a Twitter account? Or, how may the set up of the BMO Field alter fan behaviour? Giddens continually reinforces that such rules constantly dictate and manipulate human behaviour, regardless of the environment. Through the use of these two distinct theories, comparisons can be made between soccer fan communication tactics. These comparisons will be especially useful when illustrating how these fan tactics differ in social media/social networking and person-to-person communication strategies.

For the purposes of this research project, it was essential to use qualitative research 
methods to analyze and record data. Qualitative research methods allow judgements to be passed by the researcher and present more room for the analysis of static material (i.e. one hundred and forty character Twitter tweets in subject context versus word count patterns). When choosing a type of qualitative research method, I found that thematic discourse analysis was the best way to incorporate my online data on the Red Patch Boys and U-Sector with my observation notes from TFC games.

Thematic discourse analysis is a method that can be completed in a variety of different ways. In order to maintain a standard for analysis, the method chosen for this research project was taken from Virginia Braun and Victoria Clarke's article, "Using Thematic Analysis in Psychology". This article clearly defined thematic discourse analysis and illustrated the strengths and weaknesses associated with its general practice.

As defined by Braun and Clarke, "Thematic analysis is a method for identifying, analysing, and reporting patterns (themes) within data. It minimally organizes and describes your data set in (rich) detail" (Braun and Clarke 6). Most of the research used for this study centred around one subject matter, which made Braun and Clarke's method of analysis an appropriate way of categorizing any themes or patterns found within this project's documented material (i.e. how often comments pertain to the MLS, MLSE, Toronto, Red Patch Boys, and U-Sector). With that said, thematic discourse analysis was also the ideal method to analyze Twitter tweets. Many Toronto FC fans enjoy using the "retweet" feature available on Twitter, thus allowing those ideas to be shared across various fan networks. By using thematic discourse analysis, such retweets could be grouped together according to content and context and interpreted as a unified concept. 
In terms of categorization, I do not deny that some subconscious research bias may be found, as Braun and Clarke acknowledge that when researchers find themes within a text, "....it denies the active role the researcher always plays in identifying patterns/themes, selecting which are of interest, and reporting them to the readers (Taylor \& Ussher, 2001)" (Braun and Clarke 7). Within this paper, focus has been placed on a specific set of questions (How has new media affected fan cultures associated with the Toronto FC team? Do social hierarchies occur within online fan cultures? Can these results/findings be applied to other MLS franchises?), but the information collected may also hold value in analyzing other questions, ideas, and interests related to the field. So while thematic discourse analysis is effective in its simplicity, my research decisions will inherently allow one specific view to be showcased to readers.

In addition to enabling a researcher to determine what is relevant, thematic discourse analysis is also open to a variety of theoretical frameworks. As described by Braun and Clarke, “...thematic analysis is not wed to any preexisting theoretical framework, and so it can be used within different theoretical frameworks (although not all), and can be used to do different things within them" (Braun and Clarke 9). Before discussing research results, however, I will first outline the coding practices used within this project.

Considering thematic discourse analysis focuses on understanding key themes and ideas present within a text, the definition of what a theme consists of will be explored. As defined by Braun and Clarke, "A theme captures something important about the data in relation to the research question, and represents some level of patterned response or meaning within the data set...[However,] a theme might be given considerable space in some data items, and little or none 
in others, or it might appear in relatively little of the data set" (Braun and Clarke 10). When analyzing Toronto FC fan culture data, I chose to look at the following themes in no particular weighted order: Toronto FC related and fan culture hierarchy. These themes could be interpreted in a variety of ways (thanks to the flexibility of thematic discourse analysis), but in order for research findings to hold value, it was necessary to remain consistent and to have themes that could represent an entire body of collected data (i.e. unbiased or manipulated results). By maintaining a theme set prior to analyzing content, I was able to see if themes were present within text. I did not alter my themes in order to fit the content, but looked for content to fit my themes in order to relate back to my initial research questions. If a theme had not been determined prior to analysis, I could have provoked researcher bias by forcing data into certain categories to produce "ideal" outcomes. This method also allowed me to create expectations that weighted all theme categories equally, thus providing an unbiased research outlook. Braun and Clarke's description of thematic discourse analysis explains how information is sorted based on inductive or theoretical thematic analysis. For the purposes of this research project, theoretical thematic analysis was used.

In thematic analysis, the main objective is to "provide less a rich description of the data overall, and more a detailed analysis of some aspect of the data" (Braun and Clarke 12). In this case, I was interested more in my pre-established themes and research questions and chose not to acknowledge anything outside of that theoretical framework in order to avoid discrepancies within results. I chose not to use inductive thematic analysis because it is "...a process of coding the data without trying to fit it into a pre-existing coding frame, or the researcher's analytic 
preconceptions. In this sense, this form of thematic analysis is data-driven" (Braun and Clarke 12). I feel the process of inductive thematic analysis would have caused me to focus on specific ideas within the text that would then provoke different types of research questions to arise. This method would have caused me to work backwards (i.e. analyzing text and then creating research questions that would suit findings). For this particular project, inductive thematic analysis would not have garnered ideal results that were related to my research questions. In terms of how the data was to be read, I chose to use Clarke's and Braun's model that sorted themes in latent or semantic ways.

When collecting data for this research, it was important to use two different data collection types. Observations were recorded when attending game days at the BMO Field, and information was collected online from the official Twitter accounts for the Red Patch Boys (twitter.com/redpatchboys) and U-Sector (twitter.com/u_sector), the official websites for the Red Patch Boys (redpatchboys.ca) and U-Sector (U-Sector.ca), and the official website of the Toronto FC soccer team (torontofc.ca). Since the collected information ranged in its vocabulary, environment, and meaning, one should understand how to read data collected on a latent level. Latent analysis of text "starts to identify or examine the underlying ideas, assumptions, and conceptualisations-and ideologies-that are theorized as shaping or informing the semantic content of the data" (Clarke and Braun 13). Rather than just viewing data on a surface level, latent analysis requires that the researcher read all data with scrutiny and critical thinking. In latent analysis, deeper meanings can found within text, thus uncovering new information and motivations on the subjects at hand. 
Therefore, it is important to perform analysis on two fan cultures - the Red Patch Boys and U-Sector - to see how new media is affecting fandom by asking the following questions: How has new media affected fan cultures associated with the Toronto FC team? Does social networking assist in group formation? Do social hierarchies occur within online fan cultures? Can these results/findings be applied to other MLS franchises? 


\section{METHODOLOGY}

I thought it would be most appropriate to use both document collection and in-person observations when studying Toronto FC Red Patch Boys and U-Sector fans because they each allow the researcher to study fans from two distinct perspectives. Observations enabled me to study how fans interacted with one another when they communicated during face-to-face interactions at live Toronto FC soccer games. Document collection allowed me to see how fans interacted when using online text and images to discuss ideas with others part of their culture. These research techniques also enabled me to compare findings and see how communication differed between online and offline environments. It is significant to note that in order to avoid adding researcher bias, I did not act as an active participant within online fan culture communities associated with the Red Patch Boys or U-Sector, and I did not interact with fans when collecting information through observations.

Information was collected from the official Twitter accounts for the Red Patch Boys (twitter.com/redpatchboys) and U-Sector (twitter.com/u_sector), the official websites for the Red Patch Boys (redpatchboys.ca) and U-Sector (U-Sector.ca), and the official website of the Toronto FC soccer team (torontofc.ca). The online websites chosen were areas where members of the Red Patch Boys and U-Sector frequently interacted with other fans and posted comments that could be viewed within the public domain without a login. Information collected from the various websites occurred from April to June of 2011. Information documented for this research project was screened (i.e. all inappropriate or sensitive content was removed from analysis).

Observational data collection occurred from April to June of 2011 during every regular 
season home game at BMO Field. In order to ensure that I was collecting information from fans part of the Red Patch Boys and U-Sector, the attire of the fan was observed and judged for fanculture orientation. Most fans part of the Red Patch Boys and U-Sector wore clothing that bore the crest or logo of the fan culture of which they were part. When observing fans, I would document how they interacted amongst others within the stadium, where they were seated in proximity to other fans, and any commentary that they made in terms of team support/heckling. During commentary documentation, I made sure to avoid noting any information that was personal so that all data collected pertained to the game, the environment, or the fan culture. 


\section{RESULTS AND DISCUSSION}

By looking at the official websites and the official Twitter accounts of the Red Patch Boys, U-Sector, and the Toronto FC, I was able to gather some valuable insight on the various conversations and interactions that occurred between fans who were physically absent from the game day environment. With that said, I found that the themes of fan culture hierarchy and power relationships in these online environments were fascinating topics of study.

\section{Theme: Hierarchies}

My analysis of the Red Patch Boys and U-Sector accounts indicates that some form of hierarchy exists between the various individuals posting comments. This pattern was especially true with the Red Patch Boys Twitter account. According to the official Twitter page of the Red Patch Boys, there are only four individuals who hold enough power to be deemed the moderators of any comments and information posted ("Red Patch Boys"). Most comments made by these moderators focused on informing others. For instance, on May 24, 2011, these users told the public when and where they could get their supporter materials (i.e. flags, banners, drums, etc.) checked before entering the stadium. Initially, the comment read, "If you are wondering why...well we need to check drums and flags by 5:00PM...I guess \#TFC thinks we don't have real jobs" ("Red Patch Boys"). While the comment may appear to be a simple reminder, in actuality, such activity works to set up further tweets. After the tweet was posted by the RedPatchBoys user, many comments from their account followers appeared in response, which asked questions about the supporter check-in location times at the BMO Field. This activity was seen when the RedPatchBoys moderator replied to users, “@PickFunSports drums, flags, 
banners have to be checked 90 minutes prior to gates opening. 7PM start...math isn't good" (“Red Patch Boys”), and again when replying to two other users stating, “@CosmosDirector @ PickFunSports its not this day it has been in force for the last few...fortunately its easier on weekends." ("Red Patch Boys"). Thus, many of the RedPatchBoys user tweets were looked at as authoritative, informative, expert posts. These tweets not only encouraged conversation and further interaction with the public, but they also emphasized the priorities and topics under discussion for the TFC fan culture. Similarly, when I analyzed Twitter tweets posted by the official U-Sector Twitter account, a type of power relation also occurred, but to a different extent.

My analysis of the tweets posted by the U-Sector revealed that their account comments were less informative and more group-oriented. Unlike the Red Patch Boys official Twitter pages, the Twitter account of the U-Sector fan culture focused on portraying a collective, unified identity by asking questions directly to followers and addressing fans' concerns. On May 25, 2011, this occurred when the U_Sector user asked Paul Beirne, Senior Director of Business Operations for the Toronto FC team (“Team Staff”), “@Paulbeirne Can we re-print tickets? Many people's tickets were turned to mulch." ("U-Sector"). During the Vancouver Whitecaps versus Toronto FC Nutrillite Canadian Cup Final on May 25, 2011, the two Canadian MLS franchises were battling for the coveted Voyageurs Cup. Suddenly, the game was “....abandoned after 61 minutes due to heavy rain and lightning at BMO Field" (MLSSoccer.Com). The rescheduled game was held on July 02 , 2011, with the old tickets remaining valid for the new game. However, considering many fans braved the weather conditions for as long as they could 
in the stands, their tickets became useless and unreadable due to the excessive amount of rain damage. Therefore, through their tweets, the individual(s) behind the U_Sector Twitter account were acting as a collective image for fans.

Meanwhile, on another date, the users of the U_Sector account fought back against fans and critics who supported the Vancouver Whitecaps. Acknowledging that the Toronto FC may not be the best team within the MLS league, many of the comments and tweets posted by U_Sector focused on the passion, dedication, and appreciation of Toronto FC fans. On May 12, 2011 a U_Sector user critiqued the Vancouver Whitecaps lack of fan support by stating, "Congrats to the Whitecaps for setting the Cdn record for lowest ever MLS attendance tonite. Heart and soul of Cdn soccer, eh @SSouthsiders?” (“U-Sector”). Following the tweet, many Vancouver fans became outraged, which lead the U_Sector user to comment on the same day with the following tweets: "TFC's been shit for four years yet our lowest attendance is 1000 higher than what Vancouver had tonite. What's your excuse? @PrairieboyAlex", (“U-Sector"). The same user also responded to the Vancouver fan culture Blue An White Army stating, "Context must be lost on you, though. TFC drew 18,000+ in a monsoon in their first season in MLS. @BlueAnWhiteArmy” (“U-Sector"). The U_Sector account, which acts as a main gateway to the U-Sector fan culture, appeared to be a voice of reason, and a voice for all individuals part of the fan culture. Within both of these cases, the Twitter accounts of each group acted as a means to not only bring a group of people together, but to provide a voice and identity to each fan culture. Both of these examples can be related back to the arguments made by Scott Thorne and Gordon Bruner. 
In their article, “An Exploratory Investigation of the Characteristics of Consumer Fanaticism", Bruner and Thorne focus on how fans want to "... show propensity to self identify as members of fan subcultures. This characteristic is the most important, "without the desire for internal involvement (seeing oneself as a fan), the other presence of the other characteristics [of fandom] would have little import" (Bruner and Thorne 65). Fans need and desire some place where they can be identified as part of a group, and a hierarchy may be able to assist in this development. By allowing certain individuals to act as a voice, or enabling them to become the main image of a fan culture, fans are able to self-identify with a group of people without having to be involved with them face to face. Each fan culture's Twitter account acted as a gateway where fans could go to get answers, and it appeared as if there was no animosity towards those deemed as leaders. The only negative comments sent to both accounts that were available within the public domain were sent from rivalling fan cultures associated with other MLS teams. However, hierarchies may be wanted in an online setting because those who are part of a fan culture tend to desire direction (Bruner and Thorne 55). Initially fans seek fan communities in order to interact with like-minded individuals who share a common interest. Within a fan's everyday life, “...discussion of the area of interest with friends, family, and casual acquaintances who are not fans often proves unfulfilling, as they fail to approach the subject with the same level of intensity as fans do" (Bruner and Thorne 55). By having a moderator, or at least a hierarchy existing within a fan culture, online conversations can be monitored so they remain on topic and work to form an identity, which establishes what the fan culture stands for. Therefore, it appears that hierarchies are an important part of both the Red Patch Boys and U-Sector fan 
cultures because both of these groups moderate and create an online identity for all users by using social media as a platform to assist in group formation. Without these online outlets, fans may not be able to arrange to meet in person or have the ability to engage in conversation with other strangers who share the same interest. However, it is also essential to note that when looking at both fan cultures, distinct hierarchical structures occurred between the two.

In a separate analysis of the Red Patch Boys and U-Sector Twitter accounts, I found that each account authority appeared to be the voice of a specific fan culture. Yet when I took a closer look at the data (i.e. the type of comments being tweeted by U-Sector, and the amount of retweets), it appeared as if the Red Patch Boys Twitter account was the more powerful online persona. It was found that the posts made on the Red Patch Boys Twitter account between April to June of 2011 had a distinct lack of user retweets. The RedPatchBoys users frequently replied to comments posted by other individuals and also tweet their own opinions and ideas. This occurred on May 12, 2011 when the RedPatchBoys tweeted to others about, “\#supportlocalfootball shirts will be available for pick-up at Joes pre-game starting this Saturday and again prior to major academy games." ("Red Patch Boys") or on May 23, 2011, when the RedPatchBoys tweeted, "It's newsletter time!...members can find the latest version posted right here: http://bit.ly/m1vNgA \#RPBmembers" ("Red Patch Boys"). Meanwhile, the Twitter account of the U-Sector fan culture had numerous retweets. The U-Sector fan culture did not derive their own opinion often and instead would retweet content posted by Toronto FC players, officials, and other fan cultures. This pattern was seen within a May 06, 2011 tweet in which U_Sector retweeted a message originally posted by the RedPatchBoys which stated, "Join \#RPB, 
@northendelite and @U_Sector tonight at 8PM at Lamport Stadium to cheer on the \#TFC academy. Likelihood of epicness...high" (“U-Sector”). This tweet was considered to be an informative post to those part of the fan culture, and U-Sector directly retweeted this information from the original account that stated it. However, if U-Sector wanted to establish its own authoritative voice within the TFC community, the users in charge of the Twitter account would have created a new Twitter post with the same information under the U-Sector account name. That way, those following the U-Sector account would have thought that the information originated from U-Sector instead of an account belonging to an opposing fan culture. Since this retweet action is not frequently reciprocated by the official Red Patch Boys Twitter account, the U-Sector Twitter posts seem to be less elite than other TFC fan cultures. The Red Patch Boys Twitter account maintainers have more control over the information they post. The authors of the Red Patch Boys Twitter account take ownership of their tweets by stating their own opinions with each retweet. Meanwhile, the U-Sector Twitter account maintainers defer opinions to other Twitter users. This may be one of the reasons why the Red Patch Boys Twitter account has more followers than the U-Sector Twitter account (RPB 1200 followers and U-Sector 699 as of June 30, 2011). The Red Patch Boys Twitter account is more informative, personal, and garnered to a specific audience. The U-Sector Twitter account focuses more on being a generic newsfeed that compiles a vast amount of information in one place. However, a different kind of hierarchical pattern was found on the official websites and forums of both fan cultures.

An analysis of the official forums and websites of the Red Patch Boys and U-Sector fan cultures revealed that hierarchies were present in a different way than they were in their official 
Twitter accounts. Within both online forums, fans were separated into different categories which highlighted their membership status and forum privileges. Blue boxes in U-Sector forum represented the level of a fan's participation in relation to other members. The number of boxes a fan had displayed under his or her profile name indicated his or her status as a member (i.e. regular user, moderator, or forum administrator). Meanwhile, at the Red Patch Boys official forum, each fan had a different membership status tag located under his or her user name that indicated whether he or she was a Moderator, RPB Member, Registered User, or President/Past President (it is important to note that there may be additional member statuses allocated to specific members, but since the membership list is not available without a user login, such information was not included in this report). When reading the posts written on both online fan forums, I discovered that there was tension prevalent between members belonging to different online user statuses. This development could be seen in the post entitled, "Bring Your Flags Early...", located on the Red Patch Boys forum. The post was created by a user using the alias, werewolf on May 09, 2011 in regards to a negative event that occurred at BMO Field on a prior game day (werewolf). Following the comment, numerous other fans added in their opinions, though the only comments which appeared to be of significance were posted by forum Moderators and RPB Members. In this case, comments posted by people with the title of Registered User (those who do not pay for a membership with the Red Patch Boys have "Registered User" displayed as their title) were viewed as less important. Registered Users have the power to leave their own comments on the forum, however, these comments do not gain much user traffic from those who belong to a higher status (i.e. Moderator and RPB Member). 
This disregard for Registered User comments stems from the fact that they are not seen as fully dedicated fans - if they were "real" fans they would pay the yearly fees to become full-pledged members of the forum. If one of these Registered Users was to pay for a yearly membership, their status would change to RPB Member and their opinion would hold more value in the online setting. Thus, the status an individual holds in an online setting may alter the way others communicate with them. As highlighted in researcher Liz Moor's work, " how and why [fans] might function as claims to belonging that may, in turn, be connected to the exclusion, or potential exclusion, of others" (Moor 138). It is essential that there be some type of reasoning behind ranking members part of an online fan culture. The exclusion and sorting of people not only develops a stronger fan community, but assists in group formation. To further illustrate Moor's point, it was found that the comments posted by RPB Members and Moderators were viewed as significant and authoritative. Another example of this occurred during one segment of the post, RooneyRPB, where the Vice President of the Red Patch Boys posted, "This situation is a bit discouraging. Its being looked into." (RooneyRPB). Following RooneyRPB 's comment, another post was written by the President of the fan culture, Boris, which stated, "As i said earlier, things are still being worked out. We have a few options in the works to make things easy. If things dont improve we will for sure need to think about things but at the end of the day we are a supporters group, not an angry protest group." (Boris). Both of these comments were viewed highly by other members, and ended up being quoted numerous times after. The formation and acknowledgement of a hierarchical system allows for strong bonds to form between those part of each fan culture. If a hierarchy were not present and all users/members of 
a fan culture were ranked equally, conversations could be steered off topic and the overall goal of a fan culture may be forgotten.

A similar hierarchical illustration could be viewed within the U-Sector fan forum. "TFC's Security Policies, Please Provide Feedback", was a post published on the U-Sector fan forum by Ryan Keay, a forum administrator, on April 20, 2011. Within the post, Ryan Keay notified forum members of BMO Field's security policies and asked those supporting the U-Sector fan culture to provide their opinions, concerns, and suggestions on the issue. However, at the very beginning of the post it states the following, "Okay, well I [Ryan Keay] received the following from the club this morning, and I [Ryan Keay] wanted to post it to get feedback from everyone, and how we think U-Sector, as a group, should respond.” (Ryan Keay). Despite his seemingly open communication style with U-Sector fans, it must be noted that Ryan Keay is still at the top of the U-Sector fan hierarchy based on the ways the Toronto FC staff communicate with him. It appears as if a personal message was sent solely to Ryan Keay by Toronto FC staff regarding security policies. No other members part of the U-Sector forum had created a similar post thread earlier in the day, and no other members responding to Ryan Keay's post articulated that they had received the same comments from Toronto FC staff members before. Instead, because Toronto FC staff knew Ryan Keay held power within the fan culture, and would be able to deliver the message to all other members of the U-Sector community. Since Ryan Keay has been placed in a position of power, he was able to communicate security policies to all other U-Sector members using authoritative language. For instance, Ryan Keay stated, "No streamers, novelty ribbon or any items in general will be permitted under any circumstances (including goal 
celebrations) in the supporters sections. Anyone found throwing any item will be ejected." (Ryan Keay). Since he does not state if these are the verbatim words of the clubs, it has been assumed by other fans part of the U-Sector forum that Ryan Keay had access to the club's comments, summarized them, and then posted them to the U-Sector fan community. The word choices made by Keay within his posts further assert his position of power within the fan culture. Ryan Keay is not passive when he states, "under any circumstances" and "will be ejected", but uses these phrases in an assertive, authoritative manner. Many other words could have been used to state that there will be zero tolerance in regards to inappropriate fan behaviour, and he chose to direct rather than request that fans obey his posts (i.e. by stating "please do not").

All posts after Ryan Keay's forum announcement either directly commented on his content or asked questions that pertained to Ryan Keay. User Furpo asked, "What do they mean by flags and banners? All flags and banners or just those over a certain square footage? That is, can I bring in my 1m x 1m flag and pole?" (Furpo). Another user, Ultra \& Proud, stated "I somewhat understand their whole protecting the people deal due to insurance and liability issues but some of this seems... like it's just set out to make it more difficult for supporters to support the team rather than protect the public." (Ultra \& Proud). Both Furpo and Ultra \& Proud are regular users at the U-Sector fan forum and have over seven hundred posts published in addition to numerous blue boxes below their name (indicating their high status on the forum). Their opinions and comments were registered and understood by other members of the forum, which indicates that their posts positively contributed to the online fan discussion in a useful manner. On the other hand, there were some users with minimal blue boxes who provided comments to 
the post, originally posted by Ryan Keay, but were ignored or treated differently than users with more blue status boxes. Individuals with less blue boxes were treated as if their opinion did not hold value in the online setting. The more blue boxes an individual had below their username signalled that they were an avid forum poster with power, credibility, and seniority. Doctor Feelgood was one of these users who provided suggestions, concerns, and ideas to the forum, yet his comments were critiqued and criticized by other fans. Doctor Feelgood stated that the "MLSE does not care about supporter groups. They care about corporate sponsors, hi price ticket holders and merchandise from which they garnish bulk of income. Same as leafs raptors" (Doctor Feelgood). This type of comment lead to criticism from members with higher blue box numbers, such as kipl, who stated, "I doubt it's as clear cut as you make it ...They may care more about making money than the fans, but it's not one or the other. Need I remind you that they have to consider it a business?" (kip1). Not only did this type of back-and-forth conversation display a clear hierarchical structure, it also showed how individuals with lower blue box counts were viewed differently from other fans when they critiqued the Toronto FC. These individuals were viewed as less expert, and their opinions did not hold the same value. However, the forum activities of these fan cultures can be effectively explained using the Structuration Theory. According to Giddens's Structuration Theory, habits, routines, and rules influence and determine various types of human interaction (Giddens 19). Giddens states that "... all human beings are highly 'learned' in respect of knowledge which they possess, and apply, in the production and reproduction of day-to-day social encounters; the vast bulk of such knowledge is practical rather than theoretical in character" (Giddens 22). These types of interactions can range 
from learning how to speak within a conversation to remembering to check a schedule and in order to arrive on time at work. By learning how to control one's mannerisms and to follow a set of rules and societal norms, individuals learn to appear "normal". Applying Giddens's Structuration Theory to the interactions within the Red Patch Boys and U-Sector official forums provides some insight to this issue.

Giddens's definition of Structuration Theory focuses on how people recall past events in order to shape their future-this includes the rules, regulations, and other social markers that dictate how to follow societal norms within specific environments/situations (Giddens 19). Therefore, it is possible that hierarchies exist within these online forums because of the rules and routines learned as children. This can be seen in childhood where we are taught to not trust everyone instantly, especially when talking to strangers. The more accustomed people get to certain individuals, the more likely they are to trust them and share more information with them. Within both the Red Patch Boys and U-Sector fan forums, I believe this very same social orientation occurs. Fans do not trust newcomers or members who post infrequently and consequently look down upon them. The more a member posts to the online forums, however, the more he/she will experience an increase in the trust that he/she obtains from other members. This may be due to the fact that such members are considered to be a familiar voice to the fan culture community, or it may be because the more a member posts comments online, the higher their status (as indicated by blue boxes or a change in administrative privileges) will become. Either way, as in political campaigns, fan culture hierarchy is determined by the notion that one can trust another based on the appearance that he/she is immersed within the culture, cares about 
those who are part of it, and is informed about the latest current affairs surrounding the everyday lives of the people in which he/she is interacting. When I analyzed the data for hierarchies within the official websites of the Toronto FC, Red Patch Boys, and U-Sector, as well as within the recorded observations at the Toronto FC home games between April to June of 2011, I discovered that structural patterns of a different sort were present.

An analysis of official fan culture websites revealed that the theme of hierarchy was not prevalent. Each website appeared to follow the same structure: various contributors writing articles about Toronto FC players, game day events/fan culture events (Red Patch Boys and USector only), and synopses of the latest Toronto FC issues. Since there are only a few individuals who appeared to be daily/weekly contributors to all three of the websites, it is unfair to state that a hierarchy existed within these settings. Rather, it appeared as if those who were web savvy were given the authority to post content and update each website. The process did not seem to be influenced by any other factors, such as the level of fandom portrayed by the author of the post. All comments posted on each of the three websites were open, and therefore written for a large viewing audience in a language catered to those with a basic reading level. When taking all of this into consideration, these online official websites cannot be looked at as modes for community building or hierarchical structures, but as gateways or portals to the fan cultures themselves. As stated by Matthew J. Smith in his research on community building within online environments, “...the most intriguing aspects of the Internet are the possibilities it presents for the development, growth and maintenance of distance-transcending relationships" (Smith 87). At the same time, "The Web specializes in conveying information written in hypertext, that is, 
information organized in a way that makes accessing it far less time-consuming than traditional linear methods of reading (Cotkin)" (Smith 87). Official websites are made in order to attract a large audience of people who may or may not be visiting for a specific purpose. Official website webmasters/maintainers assume that users require guidance, and consequently tend to have an easy-to-follow navigation system that includes features such as a news feed, About Us section, and a gallery in order to appear welcoming to a new viewer. However, extra links are also readily available on the official websites for those who are more web savvy and desire to delve deeper into website content (i.e. Facebook pages, Twitter feeds, and online forums). These extra links serve as alternative online gateways to lead fans away from an official website and into another affiliated direction where they can meet like-minded individuals. Groups containing hierarchies are then formed using other modes of online communication such as Twitter and online forums. Similar conclusions were drawn when analyzing the data collected through observations, further reinforcing the importance of social networking tools within sport fan cultures.

While documenting and recording conversations at events that took place during Toronto FC home games between April to June 2011, I found that sports fan hierarchies did not appear to be present within game-day atmosphere. Most conversations between fans were either game related or intimately personal. On April 30, 2011, two fans located within the Red Patch Boys supporter stands wearing Red Patch Boys emblems on their clothing were discussing the high price of beer at BMO Field. One of the fans began proclaiming, "The beer here is too expensive, and sometimes it's not even completely full... If they want more people to actually show up at 
games, they [the MLSE] should make things cheaper"' (Zdzylowski). Once this was said, the responding fan began to use profanity and went off on a tangent about an unrelated issue. Considering this conversation, and many more, had no relation to the research questions being posed within this paper, they did not help to answer whether or not hierarchies exist within fan cultures at live sporting events.

Fan conversations overheard at home games were based on soccer being played on the pitch, with a mixture of Red Patch Boys and U-Sector fans cheering, chanting, and singing. The "togetherness" of individuals at games made it appear as if fans were unified and equal—a vast contrast from what was being read and deciphered within the online environment research. For instance, on game days in sections 111,112 and 113, fans wore the same red or white attire sported by the Toronto FC team. Not only did this colour scheme make the group of fans appear as a single unit, but it also showed that everyone within that section of the stadium was considered to be equal. When fans were cheering and chanting during the game, it was done in unison. No individual attempted to steal the spotlight with attention-seeking tactics. The only exception to this was during each home game when one or two fans were given a megaphone and asked to stand on a set of wooden stairs at the front of each section to lead fan chants. Even in this case, those with the megaphone acted more as orchestra conductors that notified people when to start and stop singing.

\section{Questions:}

How has new media affected fan cultures associated with the Toronto FC team? Can these results/findings be applied to other MLS franchises? 
To answer these questions, the theme of Toronto FC related material was examined within the Red Patch Boys and U-Sector fan cultures Twitter accounts, forums, and websites. However, it is important to note that the thematic discourse analysis performed for this study was not focused on seeing how frequently Toronto FC was brought up in conversation, but what type of Toronto FC topics were being discussed between fans. Did these new environments enable fans to discuss issues faster than regular media? Had new media impacted the level of fandom/knowledge acquired by fans? In the age of the Internet, content is published every minute and provides fans with information at an instant, accessible rate. An analysis of the Twitter official accounts of the Red Patch Boys and U-Sector fan cultures revealed breaking news as a prominent theme.

\section{Theme: Toronto FC Related}

Almost every tweet posted on the official Twitter accounts of the Red Patch Boys and USector was in some way Toronto FC related. Whether people were ranking a team member's playing style or critiquing a game after it had been played, it appeared that fans felt there was always a comment to be made. Yet during April to June of 2011, many comments posted on both fan culture Twitter accounts were quite involved and personal. More information, which was not made available by the Toronto FC team (or any of their direct affiliates or major media outlets), was reported by fans. By breaking news themselves fans directly illustrated the power of the Internet and online communities. This was initially seen on the Red Patch Boys official Twitter on May 06, 2011.

On May 06, 2011, the RedPatchBoys account retweeted a tweet initially posted by 
JohnMolinaro stating, "I'm back from \#TFC training. [Alan] Gordon ruled out for Sat (groin injury). Winter says everyone else fit \& available for selection. Story later.” ("Red Patch Boys"). This news was important because Alan Gordon was often one of the team's starting eleven players. Gordon's absence caused major changes in the starting eleven and impacted the game environment on May 07, 2011. Because Alan Gordon could not participate in the game, another player, Nick Soolsma, was placed in the forward position. Soolsma was a new player who had only just been signed with the Toronto FC team earlier in the 2011 season and had not been part of the starting eleven ever before. As such, many fans felt uneasy about his abilities on the field. Later that day, another post was made by the Red Patch Boys that was directed at the Toronto FC and Asifin Hossain, "Producer, digital - online for multiple sports teams \& a regular contributor to GOLTV.ca and TorontoFC.ca” (“Asif Hossain”), stating, “@torontofc @asifintoronto might want to get the web folks to update the \#TFC academy page" ("Red Patch Boys"). The Toronto FC Academy is the farm team of the Toronto FC team, meaning that they are a selected group of skilled male soccer players under the age of twenty that are training in hopes becoming part of Toronto FC or another major soccer franchise. The Toronto FC Academy plays a vital role in developing new MLS players, and several players have already been drafted to the Toronto FC and other MLS teams. While this comment made by the RedPatchBoys user may seem like a quick reminder for the Toronto FC web staff to update their content, in reality, after studying the homepage of the Toronto FC Academy, it was found that the Red Patch Boys Twitter account was indeed a more reliable, up-to-date Toronto FC news source. For example, on May 08, 2011, the RedPatchBoys user posted, “\#TFC academy kick off against Mississauga Eagles at 
Centennial at 8PM. Come out and \#supportlocalfootball" ("Red Patch Boys"), and then on May 29, 2011 the RedPatchBoys user posted, “...remember love football day is not over. Join us @U_Sector and @northendelite at the \#tfc academy game at 6" ("Red Patch Boys"). Following both of these tweets were images, videos, and other multimedia sources which showed fans during various parts of the game. Such posts may seem to be unimportant news, but the Toronto FC official website rarely reports on Toronto FC Academy games. No media reports from the games are ever published on the Toronto FC main page other than a single photo with a caption, and sometimes there is a game score highlighted with an article and accompanying photo. There is, however, a high demand for the latest Toronto FC updates because they have the potential to change a team's performance dynamic on the field. For example, the Toronto FC may win games and actually make the playoffs if new up-and-coming players are drafted early. By knowing who players are before they actually make the Toronto FC team, fans can familiarize themselves with their playing styles and can make cheers, suggestions, and fan memorabilia adorned with their names. A similar theme pattern also was observed during the study of the U-Sector Twitter account.

Analysis of the U-Sector Twitter feed for content relating Toronto FC related material showed a distinct similarity to the Red Patch Boys's Twitter activity. Most news stories highlighted on the U-Sector Twitter feed were regarded as "breaking news". However, the one difference between the two fan cultures was that the U-Sector Twitter account tended to retweet breaking news from other Twitter users - an act that illustrated that U-Sector acknowledged that other sources could also provide important updates. On May 14, 2011, the U_Sector Twitter user 
tweeted the following message initially posted by Luke Wileman (TSN Sportscaster), "Borman misses tonight's \#torontofc match for personal reasons. Yourassowsky injured” ("Luke Wileman"). This news was published hours before the soccer game on May 14, 2011 between the Toronto FC and the Chicago Fire and seemed like substantial news that would impact the game that was to be played later on that day. As an avid Toronto FC follower, I was aware that this news was not that significant. Both Danleigh Borman and Mikael Yourassowsky were new to the Toronto FC team (being signed in 2011) and had not made a significant impact on the field by mid-May. By stating that the news was coming from Luke Wileman, the "play-by-play voice of Major League Soccer on TSN in Canada" (“Luke Wileman”), U-Sector provided some credibility to its account fans and followers. Anyone could have tweeted that both Borman and Yourassowsky were going to miss the game, but retweeting a comment made by a TSN sportscaster made the information much more reliable. TSN (The Sports Network) is the primary sports channel in Canada, and in 2009 the channel was “...available in nine million homes since it launched on Sept. 1, 1984, and the network remains an important part of Canada's sports media landscape" (TSN.Ca Staff). TSN commentators and sportscasters hold prestige within the field of sports, and it is their mission to "...capture the triumphs and tears of athletes from across Canada and around the world and [to deliver] indelible moments in sports history to Canadians from coast to coast" (TSN.Ca Staff). As such, TSN is considered to be a trusted, accurate news source within Canada. If incorrect news were to be provided by their commentators, Bell Media (who owns TSN) and the channel's viewership levels would be affected negatively. When I analyzed the correlation between Toronto FC related materials and the Red Patch Boys and U- 
Sector Twitter accounts from April to June 2011, I found that their communication patterns could be related to the arguments made by Henry Jenkins.

In Jenkins's article, “The Cultural Logic of Media Convergence”, discussion is focused on the ways in which individuals use new media and technological developments in order to communicate. Jenkins explains the importance of media convergence in that "Media convergence is more than simply a technological shift. Convergence alters the relationship between existing technologies, industries, markets, genres and audiences. Convergence refers to a process, but not an endpoint" (Jenkins 34). With this argument, Jenkins questions how people form relationships with new media devices and applications and how they alter items and processes from their past. These ideas are also relevant to the Red Patch Boys and U-Sector Twitter accounts because they also partake in media convergence. These two Twitter accounts post breaking news updates and provide fans with a new outlet to obtain information. Before the advent of Twitter, fans would have had to purchase a newspaper or watch television in order to see what was happening with their favourite sports team. Today, by simply logging on to the Internet and visiting a social media website such as Twitter, information is both automatically accessible and up-to-date within minutes of it occurring. For example, both the Red Patch Boys and U-Sector Twitter accounts provide fans with frequent updates, which state team changes, event times, and anything Toronto FC related. Without the capabilities of the latest mobile technology, such information transfers would not be possible. In the past, this information was only accessible to broadcast journalists in the field who were required to go through a hierarchical process before the information could reach the public (i.e. a journalist would have to 
check an article before publishing and a television producer would need to provide authorization to fellow staff members before creating a new television news segment). The convergence happening today, however, has placed the power in the hands of fans. Fans are becoming a larger and more influential group of individuals who are breaking news and who are attempting to gain ownership of the content they report on; such transformations have posed future problems around media ownership that have yet to be resolved (Jenkins 40). Therefore, the media convergence occurring today, which is giving Toronto FC and many other fans power, is beneficial to fan cultures. Fan cultures are thriving on media convergence because of the new applications, devices, and technologies that allow them to instantly connect and report to likeminded people. Media convergence is enabling Toronto FC fans to take ownership of and to share information with a large group of people in a short period of time. I also noticed a similar conclusion when I studied how the Toronto FC related theme appeared in the official forums of the Red Patch Boys and U-Sector.

Both the Red Patch Boys and U-Sector official fan forums had sub-forums designated solely for Toronto FC related discussions. Within these sub-forums, fans could post about everything from the latest Toronto FC signings, game results, and player attire, to complaints about broadcasters that air Toronto FC matches, old Toronto FC soccer players, and supporterrelated Toronto FC chants. Most posts created between April and June of 2011 broke news that would affect the future of the Toronto FC franchise (for example, new signings, game day events, player injury reports, and match results). However, there were also numerous posts on both fan culture forums where fans would hypothesize game outcomes and act like sports 
commentators or critics. These posts would start out with one fan posing a question or stating a comment that was then followed by numerous opinion responses from other parts of the forum. Not only did this activity illustrate how educated and involved fans were in the Toronto FC franchise, it also emphasized how fan cultures used social media as a means of expression and constructive criticism. This mode of communication could especially be seen in a post at the Red Patch Boys fan forum entitled, "Do You Think JDG's [Julian de Guzman's] Performing Better This Season", which was created by user, Oldtimer on April 25, 2011.

Oldtimer, a moderator at the Red Patch Boys forum, was attempting to get the opinions of other forum members to see how they felt about Julian de Guzman's playing style during the beginning of the 2011 MLS season. Within the post, fans could either respond to a poll which had predetermined responses stating, "performing better", "performing about the same as last year", "performing worse", or "unsure" (Oldtimer), or if a fan wished to express him/herself further, could post a follow-up comment. The post by Oldtimer received numerous comments from members of the Red Patch Boys who wanted to voice their opinions on the issue. De Guzman is the highest paid MLS Canadian player with a 2011 base salary at $\$ 1,863,996.00$ (2011 Guaranteed Compensation at \$1,910,746.00) ("Player Salary Information"). He had been under harsh scrutiny from fans for not being considered a reputable return investment (i.e. de Guzman has not helped to assist Toronto FC into making playoffs or winning games). Within the post, fans did not respond to Oldtimer with simple yes or no answers, but provided their honest opinions on the subject and included supporting information in order to get their ideas across. This could be seen with a response from user, Pachuco where he stated the following: 
think [that de Guzman]'s performing better. Having said that, I wouldn't pay DP money to a guy as one dimensional as [de Guzman]. I truly believe you can find DPs that can be comparable from a defensive standpoint but can also join in the attack (Something JDG seriously lacks). [de Guzman's] assist on Saturday was real nice, but that's also as rare as it gets for JDG. I prefer big strong DMs in this league (Shalrie Joseph) or guys who will punish a player for holding on to the ball too long (Osvaldo Alonso). In both cases though I expect DMs to be able to join in the attack and make threating passes every once in a while. So although [de Guzman]'s playing better, unless he takes a massive pay cut I just can't see how JDG stays on this team beyond his contract. (Pachuco)

When frequently stating 'DP', Pachuco refers to designated player money, “... a mechanism that in 2007 began allowing an individual club to pay one player any amount above a fixed salary budget charge" (Mayers). Other players within the MLS who have obtained designated player money include Eric Hassli (Vancouver Whitecaps), David Beckham (L.A. Galaxy), and Theirry Henry (New York Red Bulls) (“Player Salary Information”). By consistently referring back to the amount of designated player money de Guzman receives, Pachuco showed knowledge and understanding of the MLS. Pachuco gave additional information to support his argument and to persuade readers (i.e. discussing de Guzman's playing style and then comparing him to others part of the MLS that play in the midfield position for less pay) instead of just stating the obvious and commenting solely on de Guzman's playing style. The Red Patch Boys and U-Sector fans observe all things related to the Toronto FC and take note of what happens with other MLS teams. Not only does this practice allow fans to have intricate conversations, it also enables them to become critics and gain validity/respect when defending their beliefs. Shortly after Pachuco's post, many other members felt the need to comment on the arguments made. A user called Hustle 
responded to Pachuco's comments, stating:

${ }^{\wedge}$ This argument about any wage above $350 \mathrm{k}$ being no relevance to the fan does not float in my opinion. There is ALWAYS a limit to the resources available to sign players. If JDG takes $1.7 \mathrm{~m}$ of those resources, it means less is available for the next possible $2 \mathrm{nd}$ or third $\mathrm{dp}$ signing. That is important to me as a fan. Just because the cap hit is $350 \mathrm{k}$, doesn't mean we shouldnt be concerned that he eats another $1.35 \mathrm{~m}$ of money that he isnt worth. Otherwise, you might as well say pay him 5million a year, because whats the difference? It matters. (Hustle)

Many other posts followed this back-and-forth exchange between Pachuco and Hustle, and throughout this communication, a common theme emerged. Fans continually attempted to change the opinions of others and simultaneously tried to provide insightful perspectives on the issue. No user was ever one hundred percent supportive of another fan's opinion, and each author felt that they were correct in their opinions. Not only did such activity show how determined and narrow-minded some fans were, but it illustrated how anti-fan activity can occur within a fan culture environment.

Jonathan Gray explains that anti-fans are part of "....the realm not necessarily of those who are against fandom per se, but of those who strongly dislike a given text or genre, considering it inane, stupid, morally bankrupt and/or aesthetic drivel" (Gray 70). In this case, each individual was educated and constructed his/her own opinion of de Guzman based on Toronto FC performance. By not accepting the opinions of others, fans constructed an image of de Guzman, “....an image they feel [was] accurate-sufficiently enough that they [could] react to and against it" (Gray 71). If this image was not created, fans would not have had anything to 
react to - negatively or positively. Instead, fans would passively accept the opinions of others and simply respond to the post poll's generic responses. Therefore, it appears as if new media (i.e. online forums) were enabling fans to become anti-fans and show their true feelings on issues surrounding the fan culture. Before the advent of the Internet, fans did not have the tools to express themselves so openly to a large, active audience, and had to rely on modes of communication that filtered select comments to publish (newspaper opinion columns, for example). In an online setting, fans could express their dislikes and then defend them in a multidimensional way. This type of fan culture communication can be related back to Bonnie A. Nardi's definition of Activity Theory.

Nardi states, "Activity theory is a powerful and clarifying descriptive tool rather than a strongly predictive theory. The object of activity theory is to understand the unity of consciousness and activity" (Nardi 7). Activity Theory is commonly linked to human-computer interaction (HCI), and focuses primarily on the idea that "the nature of any artifact can be understood only within the context of human activity by identifying the ways people use this artifact, the needs it serves, and the history of its development” (Kaptelinin 46). Such development may give a reason as to why anti-fans exist within fan cultures. Anti-fans are fans who participate in online communities and social networking applications due to their accessibility. If these new devices and applications did not exist, anti-fans would not be a prevalent force within fan cultures and consequently keep their opinions hidden from public face-to-face interactions. However, since social media applications are so readily available, antifans have a new outlet where they may participate in criticism without damaging their in-person 
reputation. For instance, today, anyone can go online and register for a free Twitter or Facebook account using fictitious information. Since a person's identity is false, he/she can then post a multitude of comments without the outside world ever discovering his/her true identity. Not only does this practice save face, it also enables people to have two different identities (online/offline). Taking into account Nardi's idea of understanding the development of new artifacts and devices, one must consider how Twitter and other social networking devices were created. Were these online devices initially developed to help connect fans, or were there other reasons behind their creation? This may be an area for further research interest. However, when looking at the official websites of the Red Patch Boys and U-Sector, a different conclusion was reached about the ways in which Toronto FC related material is displayed.

When I analyzed the official websites of the Red Patch Boys and U-Sector fan cultures, I found it difficult to determine how the theme of Toronto FC related material was present. Both websites functioned as online portals and provided fans with social media outlets where they could read the latest team news and connect to other fans. Having links to social media websites available on each fan culture's official website caused each of these sites to become static. These websites acted as a synopsis of the team by giving a brief overview of both fan cultures' beliefs, origins, and fandom, and provided other online outlets where fans could become more actively involved. The Red Patch Boys website was rarely updated - only a top banner changed to show when the next Toronto FC game day was to be held. There also was no discussion between fans on the website. During April-June of 2011, the Red Patch Boys website focused on the "Support Local Football" campaign, a campaign which was not related to just Toronto FC. Therefore, it 
seemed inappropriate to come to a conclusion based on what was displayed on the Red Patch Boys website because it failed to represent its fan culture as a whole. When visiting the U-Sector website, I found that it was updated more frequently, but also lacked content pertaining to Toronto FC. With a blog-style news feed located on the website's main page, the U-Sector website consistently informed fans when an upcoming game would be held and where meetings would take place before and after games; however, there was also a lot of unnecessary and offtopic dialogue posted. For example, on April 20, 2011, an update was posted entitled, "Bleed Red, Piss Yellow”. Within the post, "Bleed Red, Piss Yellow”, comments stated: "Everybody make sure you're up to date on all your shots, as the Crew are due to make their way into town." (“Bleed Red, Piss Yellow”). Despite referring to fans of the Columbus Crew in this crude manner, this U-Sector website post did not relate to the Toronto FC related research theme being searched for, but illustrated how mean-spirited others can be when using social media. New media enabled those participating in fan cultures to challenge societal norms of politeness that would normally result in social alienation or backlash in the offline world. As a result, fans have become online warriors that use the anonymity of the computer screen as a shield to protect them against the consequences of their sometimes questionable behaviour. Further research could be conducted to investigate if fans would be as open with their negative comments in the offline world. Though, at the moment, social media has overpowered the official websites of both fan cultures and the Toronto FC. 


\section{CONCLUSION}

After analyzing the Red Patch Boys and U-Sector fan communities, as well as the official website of the Toronto FC team, I have gained a new appreciation for Toronto FC fans. Toronto FC fans are loyal, unique, and dedicated individuals who have modified their lifestyles in order to support the Toronto FC. They are well-educated about the Toronto FC franchise and have used social networking and social media in order to form fan culture communities that have a unified purpose. When starting this research project, I wanted to know how new media affected fan cultures associated with the Toronto FC team, if social networking assisted in group formation, if social hierarchies occurred within online fan cultures, and if these results could be applied to other MLS franchises. However, there were limitations to these field questions because it was difficult to come to a conclusion after analyzing data from only April to June of 2011. Despite these shortcomings, my results provided some insight on the subject and inspired certain patterns to be recognized that may have been overlooked by someone performing Thematic Discourse Analysis.

During my research analysis, the power of social media, new media, and social networking became apparent. The Red Patch Boys and U-Sector fan cultures used Twitter and online forums as a way of breaking news, forming strong relationships, and communicating in a time-efficient manner. These online applications allowed fans to meet from distant geographical locations and enabled them to share numerous pieces of information which would have not have been possible otherwise. This constant communication between fans not only assisted in group formation, but permitted fans to interact and discuss all things related to Toronto FC (i.e. trades 
before they occurred or breaking news before an official announcement) in a new way. It was also discovered that hierarchies were prevalent amongst members using online applications, and such hierarchical structures affected the way in which fan communication was received and accepted. How active a fan's presence was online and how high their forum/Twitter reputation seemed to influence whether or not his/her opinions would be trusted by others part of the fan culture. The online hierarchies on Twitter and Facebook seemed to disappear in an offline environment because fans acted as a unified force. Therefore, if further research were to be done on these two fan cultures, it would be significant to look at how hierarchies exist in offline versus online communities and why such a difference exists. It would also be beneficial to collect data from two different Toronto FC seasons to see if fandom trends change annually, or if certain fan behaviours are an ongoing trend. Through my research I found that findings may be applicable to other sports fan cultures that have a dedicated following to a losing team (ex. Toronto Blue Jays, Toronto Maple Leafs), but not to those who worship a team that is successful. The lack of achievements made by the Toronto FC in conjunction with the continuing rise of ticket prices by the MLSE may be affecting the opinions held by fans, and the ways fans interact using online media. This research project also contributed information to the field of fandom, fan cultures, and new media.

There is minimal research that explores the effects of new media and fan cultures. With that said, few researchers have even attempted to study the social repercussions of using online social applications such as Twitter. As the number of tweets per day increases around the world and new social media applications become more widespread, it is evident that the ways in which 
fans communicate will drastically change from the methods used less than a decade ago. This paper therefore articulates how one group of fans (part of two different fan cultures) have used new media, social networking, and online applications in order to communicate. By viewing both the Red Patch Boys and U-Sector Twitter accounts, online forums, and official websites, my research data indicated how fan cultures use online applications and questions how new media has impacted fan culture formation. How may fan cultures dictate or modify online applications? Do social media applications enhance the longevity of a fan culture? How have new media and social networking devices modified older fan cultures? While the results collected for this paper may only be applicable to other fan cultures or online communities who admire losing sports teams, this project provides an initial framework for addressing a larger issue. Fan cultures exist and are related to almost everything in popular culture. They are a substantial force, which may dictate the longevity of new social networking applications or media devices, and thus require more research and analysis. 


\section{WORKS CITED}

"Asif Hossain." Twitter. Twitter. Web. 10 June 2011.<https://twitter.com/\#!/asifintoronto>.

"Bleed Red, Piss Yellow." U-Sector. 20 Apr. 2011. Web. 15 June 2011. <http://usector.ca/wp/2011/04/20/bleed-red-piss-yellow/>.

Boris. "Bring Your Flags Early...." 9 May 2011. Red Patch Boys Forums.

12 May 2011. <http://www.redpatchboys.ca/forums/showthread.php?t=27964>.

Braun, Virginia, and Victoria Clarke. "Using Thematic Analysis in Psychology." Qualitative Research in Psychology 3.2 (2006): 77-101.

CNW. "BMO Field, MLSE Delivers Financial Return to City of Toronto." CNW. CNW Group Ltd., 23 Feb. 2011. Web. 07 June 2011.<http://www.newswire.ca/en/releases/archive/ February2011/23/c5131.html>.

Doctor Feelgood. "TFC's Security Policies, Please Provide Feedback." 22 Apr. 2011. U-Sector Forums. 25 Apr. 2011. <http://z15.invisionfree.com/U_Sector/index.php?showtopic= $14869 \& \mathrm{st}=255>$.

Fitz-Gerald, Sean. "Is TFC Major League Soccer's Worst Team?" National Post. Postmedia Network Inc, 06 June 2011. Web. 07 June 2011.

$<$ http://sports.nationalpost.com/2011/06/06/we-pretty-much-rank-where-we-are-on-the - table/>.

Furpo. "TFC's Security Policies, Please Provide Feedback.” 20 Apr. 2011. U-Sector Forums. 23 Apr. 2011.<http://z15.invisionfree.com/U_Sector/index.php?showtopic $=14869 \& \mathrm{st}=30>$. 
Giddens, Anthony. "Elements of the Theory of Structuration." The Constitution of Society:

Outline of the Theory of Structuration. Berkeley: University of California, 1984. 1-40.

Gray, Jonathan. "New Audiences, New Textualities: Anti-fans and Non-fans." International Journal of Cultural Studies 6.1 (2003): 64-81.

Hustle. "Do You Think JDG's Performing Better This Season.” 25 Apr. 2011. Red Patch Boys Forums. 27 Apr. 2011. <http://www.redpatchboys.ca/forums/showthread.php?t=27803>. Jenkins, Henry. "The Cultural Logic of Media Convergence." International Journal of Cultural Studies 7.1 (2004): 33-43.

Kaptelinin, Victor. Context and Consciousness: Activity Theory and Human-Computer Interaction. Ed. Bonnie A. Nardi. Cambridge: MIT, 1996. 45-68.

kip1. "TFC's Security Policies, Please Provide Feedback.” 22 Apr. 2011. U-Sector Forums. 25 Apr. 2011. < http://z15.invisionfree.com/U_Sector/index.php?showtopic= $14869 \&$ st $=255>$.

"Luke Wileman." Twitter. Twitter. Web. 10 June 2011.<https://twitter.com/\#!/LukeWileman>. Mayers, Joshua. "Major League Soccer Adds Second DP Slot, Can Purchase a Third (league Release)." The Seattle Times. The Seattle Times Company, 01 Apr. 2010. Web. 01 July 2011. <http://seattletimes.nwsource.com/html/soundersfcblog/2011498898_major_league _soccer_adds_secon.html\#continue>.

MLSSoccer.Com. "Toronto-Vancouver Take One." Toronto FC. Major League Soccer, 28 June 2011. Web. 28 June 2011. <http://www.torontofc.ca/news/2011/06/toronto-vancouvertake-one>. 
Moor, Liz. "Sport and Commodification: A Reflection on Key Concepts." Journal of Sport \& Social Issues 31.2 (2007): 128-42.

Nardi, Bonnie A. "Activity Theory and Human-Computer Interaction." Context and Consciousness: Activity Theory and Human-computer Interaction. Cambridge: MIT, 1996. 7-16.

Oldtimer. "Do You Think JDG's Performing Better This Season.” 25 Apr. 2011. Red Patch Boys Forums. 27 Apr. 2011. <http://www.redpatchboys.ca/forums/showthread.php?t=27803>. Pachuco. "Do You Think JDG's Performing Better This Season.” 25 Apr. 2011. Red Patch Boys Forums. 27 Apr. 2011. <http://www.redpatchboys.ca/forums/showthread.php?t=27803>. "Player Salary Information." Major League Soccer Players Union. Major League Soccer Players Union, 01 May 2011. Web. 30 June 2011.

$<$ http://www.mlsplayers.org/salary_info.html $>$.

Red Patch Boys. 2007. Web. 02 June 2011. <http://www.redpatchboys.ca/>.

"Red Patch Boys." Twitter. Twitter. Web. 01 June 2011.<https://twitter.com/\#!/redpatchboys>. RooneyRPB. "Bring Your Flags Early...." 9 May 2011. Red Patch Boys Forums.

12 May 2011. <http:/www.redpatchboys.ca/forums/showthread.php?t=27964>.

Ryan Keay. "TFC's Security Policies, Please Provide Feedback.” 20 Apr. 2011. U-Sector Forums. 23 Apr. 2011. <http://z15.invisionfree.com/U_Sector/index.php?s=39c1644a928 4ae7a14cc9a2c461dc7fa\&showtopic $=14869 \&$ st $=0>$.

Smith, Matthew J. "Strands in the Web: Community-Building Strategies in Online Fanzines." Journal of Popular Culture 33.2 (1999): 87-99. 
"Statistics." MLSsoccer.com. Major League Soccer, 2011. Web. 10 June 2011. $<$ http://www.mlssoccer.com/stats/team $>$.

"Team Staff." Toronto FC. Major League Soccer. Web. 10 June 2011. $<$ http://www.torontofc.ca/team-staff $>$.

Thorne, Scott, and Gordon C. Bruner. "An Exploratory Investigation of the Characteristics of Consumer Fanaticism." Qualitative Market Research: An International Journal 9.1 (2006): 51-72.

Toronto FC. Major League Soccer, 2011. Web. 02 June 2011. <http://www.torontofc.ca/>.

"Troll 2 - Rotten Tomatoes." Rotten Tomatoes. Flixster. Web. 01 June 2011. $<\mathrm{http}: / /$ www.rottentomatoes.com/m/troll-2/>.

"Troll 2 (The 20th Anniversary Nilbog Edition)." Amazon.com. Amazon.com, Inc. Web. 13 May 2011. <http://www.amazon.com/Troll-20th-Anniversary-Nilbog-Bluray/dp/B003ZD9E24>.

TSN.Ca Staff. "TSN Celebrates 25 Years of Sports Broadcasting." TSN. Bell Media, 01 Sept. 2009. Web. 20 June 2011. <http://www.tsn.ca/tsn25/story/?id=289509>.

Ultra \& Proud. "TFC's Security Policies, Please Provide Feedback." 20 Apr. 2011. U-Sector Forums. 23 Apr. 2011. < http://z15.invisionfree.com/U_Sector/index.php?sho wtopic $=14869 \& \mathrm{st}=0>$.

U-Sector. 2011. Web. 01 June 2011. <http://u-sector.ca>

"U-Sector." Twitter. Twitter. Web. 01 June 2011. <https://twitter.com/\#!/u_sector>. werewolf. "Bring Your Flags Early...." 9 May 2011. Red Patch Boys Forums. 
12 May 2011. <http://www.redpatchboys.ca/forums/showthread.php?t=27964>.

Wolstat, Ryan. "Bizarre Tie for TFC." Canoe. Canoe Inc., 16 Oct. 2010. Web. 03 June 2011. $<$ http://slam.canoe.ca/Slam/Soccer/TorontoFC/2010/10/16/15717231.html>.

Zdzylowski, Andrea. Toronto FC Vs. Houston Dynamo. BMO Field, Toronto, ON. 23 May 2011. Observation Notes.

Zinchenko, Vladimir P. "Developing Activity Theory: The Zone of Proximal Development and Beyond." Context and Consciousness: Activity Theory and Human-computer Interaction. Ed. Bonnie A. Nardi. Cambridge: MIT, 1996. 283-324. 